\title{
Evolutionary implications of permanent odd polyploidy in the stable sexual, pentaploid of Rosa canina L
}

\author{
KY Lim ${ }^{1}$, G Werlemark ${ }^{2}$, R Matyasek ${ }^{3}$, JB Bringloe ${ }^{4}$, V Sieber ${ }^{4}$, H El Mokadem ${ }^{5}$, J Meynet ${ }^{5}$, J Hemming ${ }^{1}$, \\ AR Leitch ${ }^{1}$ and AV Roberts ${ }^{4}$ \\ ${ }^{1}$ School of Biological Sciences, Queen Mary, University of London, London E1 4NS, UK; ${ }^{2}$ Balsgård-Department of Crop Science, Swedish \\ University of Agricultural Sciences, Fjalkestadsvagen 495, S-291 94 Kristianstad, Sweden; ${ }^{3}$ Institute of Biophysics, Academy of Sciences \\ of the Czech Republic, Kralovopolska 135, CS-61265 Brno, Czech Republic; ${ }^{4}$ School of Health and Bioscience, University of East London, \\ Romford Road, London E15 4LZ, UK; INRA, Station d'Amélioration des Plantes Florales, La Gaudine-Frejus, 83370 Saint-Aygulf, \\ France
}

In Rosa canina $(2 n=5 x=35)$, the pollen and ovular parents contribute, respectively, seven and 28 chromosomes to the zygote. At meiosis I, 14 chromosomes form seven bivalents and 21 chromosomes remain as univalents. Fluorescent in situ hybridization to mitotic and pollen mother cells (PMC) of $R$. canina showed that 10 chromosomes (two per genome) carry ribosomal DNA (rDNA) loci. Five chromosomes carry terminal 18S-5.8S-26S rDNA loci; three of these also carry paracentric $5 S$ rDNA loci and were designated as marker chromosomes 1. Five chromosomes carry only $5 S$ rDNA loci and three of these were designated as marker chromosomes 2 . The remaining four of the 10 chromosomes with rDNA loci were individually identifiable by the type and relative sizes of their rDNA loci and were numbered separately. At PMC meiosis, two marker chromosomes 1 and two marker chromosomes 2 formed bivalents, whereas the others were unpaired. In a gynogenetic haploid of $R$. canina $(n=4 x=28)$, obtained after pollination with $\gamma$-irradiated pollen, chromosomes at meiosis I in PMC remained predominantly unpaired. The data indicate only one pair of truly homologous genomes in $R$. canina. The 21 unpaired chromosomes probably remain as univalents through multiple generations and do not recombine. The long-term evolutionary consequence for the univalents is likely to be genetic degradation through accumulated mutational change as in the mammalian $Y$ chromosome and chromosomes of asexual species. But there is no indication that univalents carry degenerate $5 \mathrm{~S}$ rDNA families. This may point to a recent evolution of the $R$. canina meiotic system.

Heredity (2005) 94, 501-506. doi:10.1038/sj.hdy.6800648 Published online 16 March 2005

Keywords: chromosome pairing; gynogenetic haploid; allopolyploid; 18S-5.8S-26S rDNA loci; 5S rDNA loci

\section{Introduction}

The genus Rosa includes species with ploidy levels that range from diploid to octoploid, the base chromosome number is 7 and aneuploids are rare. In the section Caninae, which includes tetraploid $(2 n=4 x=28)$, pentaploid $(2 n=5 x=35)$ and hexaploid $(2 n=6 x=42)$ species, a remarkable system of matroclinal inheritance has evolved. The pollen transmits only one genome $(n=7)$, and the ovule transmits one genome less than the somatic number $(n=21,28$ or 35$)$. Seven bivalents are formed in the first division of meiosis. The other chromosomes remain as unpaired univalents and their differing fates in the pollen mother cells (PMC) and embryo-sac mother cells (EMC) determine the asymmetric inheritance in this group of species (Blackburn and Heslop-Harrison, 1921; Täckholm, 1922; Hurst, 1931; Erlanson, 1933; Gustafsson, 1944; Blackhurst, 1948; Roberts, 1975; Wylie, 1976). In PMC (see Figure 1), both the bivalents and univalents divide and segregate at

Correspondence: KY Lim, School of Biological Sciences, Queen Mary, University of London, London E1 4NS, UK. E-mail: y.k.lim@qmul.ac.uk Received 29 July 2004; accepted 5 January 2005; published online 16 March 2005 anaphase I. At anaphase II the daughter chromosomes from the bivalents divide and segregate. However, the chromatids derived from the univalents do not segregate since they are unable to divide a second time. These chromosomes remain in the centre of the cell in the region of the metaphase plate where they form micronuclei, and are excluded from the tetrads. In the EMC, the bivalents divide and segregate at anaphase I. The univalents do not divide, but they do collect at one pole. At anaphase II, the chromosomes at the pole containing all the undivided univalents and a set of daughter chromosomes from the bivalents divide to give two cells each with $n=28$ chromosomes, one of which develops as the ovum.

Two triploid species, Leucopogon juniperinus (Smith-White, 1948) and Andropogon ternatus (Norrmann and Quarin, 1987), resemble the Caninae in that a pair of genomes forms bivalents and the other genome forms univalents at meiosis. However, the undivided univalents are retained at one pole at telophase I in both PMC and EMC and divide only in division II. Cells with and without the univalent-derived chromosomes are present at the tetrad stage, but the functional pollen and ovules differ in whether or not they contain the univalents. The univalents are contained in the ovules of L. juniperinus 


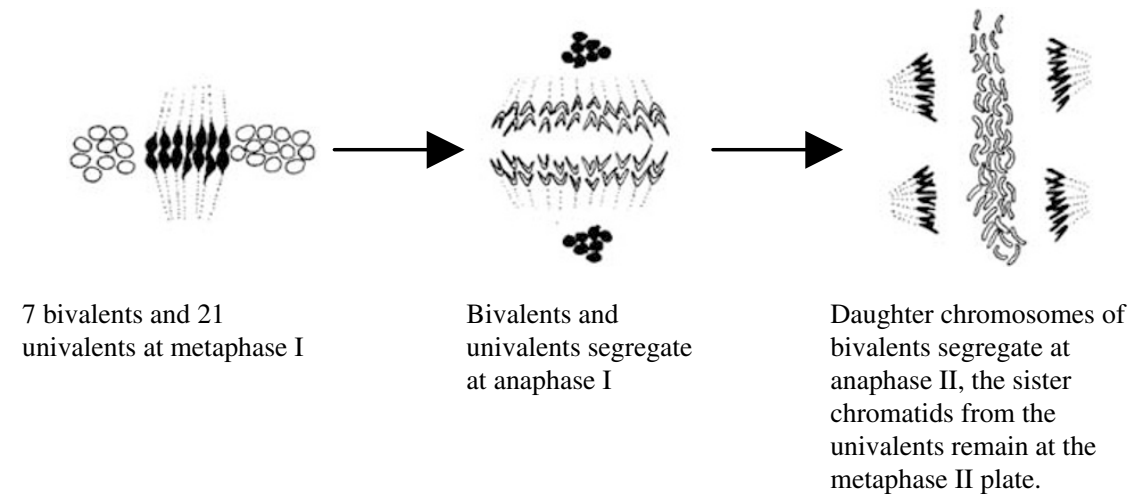

Figure 1 Schematic diagram of Rosa canina PMC meiosis. Redrawn from Wylie (1976).

and the pollen of $A$. ternatus. Thus, the type of meiosis shown by the Caninae is unique among plant species that have been investigated. It is not only in the inheritance of 'permanent odd polyploidy' (sensu Grant, 1981) that unusual stable meiosis exist. Unusual meiotic systems are also found elsewhere, for example, in the inheritance of B chromosomes (see Jones and Rees, 1982) and in the segregation of chromosomes in hybrid plants (eg Lim et al, 2001).

In Caninae, the regularity with which only seven bivalent and no multivalent associations occur at division I of meiosis suggests that two genomes are homologous and that the other genomes are heterologous. Three investigations have provided evidence that genetic markers of two genomes are closely similar to each other but are distinct in each of the other genomes. Werlemark et al (1999) showed that, in reciprocal crosses between two pentaploid species, more than half the somatic RAPD markers were transmissible only through the female parent, Wissemann (1999) detected only four distinct alleles of internally transcribed spacers of the 18S-5.8S-26S (18-26S) ribosomal DNA (rDNA) unit in a pentaploid species, and Nybom et al (2004) found only four different microsatellite alleles at each of several loci in three pentaploid species and only three different alleles at several loci in a tetraploid species. Nybom et al (2004) concluded that the bivalent chromosomes were highly similar. Darlington (1965) came to the same conclusion on the evidence of higher frequencies of chiasma per bivalent in the Caninae than other sections of Rosa. Other investigations have provided evidence of a potential for pairing between chromosomes of the other genomes that is suppressed by a genetic control mechanism. For example, Blackhurst (1948) found in several interspecific hybrids, in which $R$. rubiginosa (section Caninae) was the female parent and species of the Caninae or other sections were the male parents, that the frequencies of bivalent associations were consistently greater than seven and that multivalent associations were frequent. Gustafsson (1944) and Roberts (1975) observed similarly increased chromosome associations in other interspecific hybrids in which species of the Caninae were female parents. Blackhurst (1948) deduced that meiosis is controlled by an allelomorphic series of genes and that two homozygous alleles must be present if meiosis is to be effectively regulated. Werlemark (2003) drew similar conclusions and proposed that these alleles are located on the pairing chromosomes. Erlanson (1933) attributed nonsynapsis of the univalent chromosomes to their late condensation at prophase I of meiosis and it is possible that this is the target of the genetic control mechanism.

In evolutionary terms, the Caninae benefit from a combination of fitness (from the conservation of the unpaired genomes), flexibility (from recombination between the pairing genomes) and vigour (from the presence of three, four or five different genomes). In the rose trade, rootstock selections of $R$. canina are propagated, true-to-type, from seed raised in open-pollinated orchards, whereas rootstocks raised from species of other sections must be propagated from cuttings in order to retain uniformity. In order to better understand the evolution of the Caninae and to breed varieties of the Caninae with improved hip production for the food industry (Uggla and Nybom, 1999), more information is needed about the genomes of the Caninae and genomic similarities between species of the Caninae and other sections. In the present investigation, cytological markers of differences between genomes in $R$. canina $(2 n=5 x=35)$ were sought using fluorescent in situ hybridization (FISH) applied to rDNA loci. Evidence of pairing in nonhomologous genomes was also studied in a gynogenetic haploid of $R$. canina $(2 n=4 x=28)$ that was obtained by self-fertilization with pollen that had been inactivated by gamma irradiation.

\section{Materials and methods}

\section{Chromosomes at mitosis and meiosis}

Chromosome studies were carried out on a plant of $R$. canina L. collected in Epping Forest, London, UK and a gynogenetic haploid. The gynogenetic haploid was obtained by fertilizing a pentaploid specimen of $R$. canina with pollen that had been rendered genomically unstable by irradiation with $\gamma$-rays (600 Gy), and rescuing the embryo in vitro (Meynet et al, 1994). Herbarium specimens of $R$. canina and the gynogenetic haploid are at Queen Mary, University of London.

Root-tips were pretreated with a saturated aqueous solution of Gammexane ${ }^{\mathbb{R}}$ (hexachlorocyclohexane, Aldrich) at room temperature for $3.5 \mathrm{~h}$, fixed in glacial acetic acid:absolute alcohol (1:3) and stored at $-20^{\circ} \mathrm{C}$ until used. Roots were then washed in enzyme buffer 
(4 $\mathrm{mM}$ citric acid and $6 \mathrm{mM}$ sodium citrate) and digested in enzyme solution containing $0.3 \%(\mathrm{w} / \mathrm{v})$ cellulase R10 and $0.3 \%(\mathrm{w} / \mathrm{v})$ pectolyase Y23 and $0.3 \%(\mathrm{w} / \mathrm{v})$ driselase for $30 \mathrm{~min}$ and left in enzyme buffer for 3-4h. The meristem tips were dissected and placed on a chromicacid-washed slide, macerated in a drop of $60 \%$ glacial acidic acid to release protoplasts and squashed gently under a coverslip. For meiotic studies, fixed anthers were dissected out of young buds (14-17 mm sepal length) and digested with enzymes, as for root-tips but for extended periods.

FISH was applied to mitotic and meiotic chromosomes of the pentaploid specimen of $R$. canina using nuclear rDNA probes for 18-26S and 5S rDNA. The 18-26S rDNA probe was obtained from a $9 \mathrm{~kb}$ EcoRI fragment, pTa71, isolated from Triticum aestivum, which contains the genic subunits and intergenic spacers (Gerlach and Bedbrook, 1979). The 5S rDNA was obtained from $R$. canina genomic DNA extracted by the method of Holm (1995) and amplified by PCR with an MJ Research thermocycler under the following conditions: $0.1 \mu \mathrm{g}$ total genomic DNA, $0.5 \mu \mathrm{M}$ each primer, $0.2 \mathrm{mM}$ each $\mathrm{dNTP}$ and Dynazyme II DNA polymerase in a total volume of $50 \mu \mathrm{l}$. DNA was amplified with 5SLF 5'-CCT GGG AAT TCC TGG TGT T-3 ${ }^{\prime}$ and 5SLR 5'-TGC GTT AAA GCT TGT ATG ATC GCA T-3' primers from 5S rDNA gene using $30 \mathrm{PCR}$ cycles $\left(94^{\circ} \mathrm{C}\right.$ for $20 \mathrm{~s}, 55^{\circ} \mathrm{C}$ for $45 \mathrm{~s}, 72^{\circ} \mathrm{C}$ for $60 \mathrm{~s})$ followed by $10 \mathrm{~min}$ extension at $72^{\circ} \mathrm{C}$. Both probes were labelled by nick translation (Leitch et al, 2001) using digoxigenin 11-dUTP and biotin 16-dUTP, respectively. Slides were denatured in $70 \%(\mathrm{v} / \mathrm{v})$ formamide in $2 \times$ SSC ( $0.3 \mathrm{M}$ sodium chloride, $0.03 \mathrm{M}$ sodium citrate) at $71^{\circ} \mathrm{C}$ for $2 \mathrm{~min}$. The hybridization mixture contained $4 \mu \mathrm{g} / \mathrm{ml}$ labelled probe and $50 \%(\mathrm{v} / \mathrm{v})$ formamide, $10 \%$ (w/v) dextran sulphate and $0.1 \%(\mathrm{w} / \mathrm{v})$ sodium dodecyl sulphate in $2 \times$ SSC. After overnight hybridization at $37^{\circ} \mathrm{C}$, the slides were washed in $20 \%$ (v/v) formamide in $0.1 \times$ SSC at $42^{\circ} \mathrm{C}$ at an estimated hybridization stringency of $80-85 \%$. Sites of probe hybridization were detected using $20 \mu \mathrm{g} / \mathrm{ml}$ fluorescein-conjugated antidigoxigenin IgG (Roche Biochemicals) and $5 \mu \mathrm{g} / \mathrm{ml}$ Cy3-conjugated avidin (Amersham Pharmacia) in $4 \times$ SSC containing $0.2 \%(\mathrm{v} / \mathrm{v})$ Tween 20 and 5\% (w/v) bovine serum albumin. Chromosomes were counterstained with $2 \mu \mathrm{g} / \mathrm{ml} 4^{\prime}$,6-diamidino-2-phenylindole (DAPI) in $4 \times$ SSC, mounted in Vectashield (Vector Laboratories) medium, examined using an epifluorescent microscope fitted with an Orca ER camera and Open Lab software ${ }^{\mathbb{R}}$ (Improvision). All images were processed using Adobe Photoshop $^{\mathbb{R}}$ and treated uniformly for colour contrast and brightness.

\section{Restriction endonuclease digestion and Southern \\ hybridization}

Methods followed Sambrook et al (1989). Genomic DNA was digested to completion with excess of restriction endonuclease $\mathrm{BamH} 1$ and fractionated in 2\% agarose by gel electrophoresis. DNA was transferred to a Hybond N + membrane (Amersham Pharmacia Biotech). Southern hybridization was carried out under high-stringency conditions (Fulnecek et al, 2002) using a heat-denatured ${ }^{32} \mathrm{P}$-labelled 5S rDNA gene as hybridization probe. The $5 S$ rDNA was prepared as for FISH and the probe was labelled by a random primed method using ${ }^{32} \mathrm{P}-\mathrm{dCTP}$ (Dekaprime kit, Ambion ${ }^{\mathrm{TM}}$, USA).

\section{Results}

Chromosome segregation at meiosis in $R$. canina and the gynogenetic haploid

Meiosis in PMC of our specimen of R. canina was similar to that previously described for the species. At metaphase I, seven bivalents and 21 univalents were regularly seen (Figure 2a, Table 1). At anaphase I, the seven bivalents and 21 univalents segregate to each pole (Figures 1 and 2b). At anaphase II, the daughter chromosomes of the bivalents split into chromatids and segregate to the poles (Figure 2c) but the chromatids from the univalents, being unable to divide again, do not segregate and form micronuclei at late telophase II.

In PMCs of the gynogenetic haploid, bivalent and trivalent associations occurred, but only in low frequency (Table 1). At anaphase I, the chromosomes segregated to opposite poles, and in division II the chromatids from the univalents formed irregular groups that were enclosed in microcytes and no functional pollen grains were formed.

\section{FISH with rDNA probes in $R$. canina and the gynogenetic haploid}

FISH applied to metaphase cells at mitosis and meiosis revealed five $18 \mathrm{~S}-26 \mathrm{~S}$ rDNA loci (Figure $2 \mathrm{~d}-\mathrm{h}$, fluorescing red) and eight 5S rDNA loci (Figure 2d-h, fluorescing green) on 10 small submetacentric chromosomes. The 18S-26S rDNA loci were at the ends of the short arms and the 5S rDNA loci were adjacent to the centromeres on the long arms. Two groups of three chromosomes and four individual chromosomes that could be identified by these loci were assigned numbers. Three chromosomes (marker chromosomes 1) carried 18S-26S rDNA and 5S rDNA loci. Three chromosomes (marker chromosomes 2) carried 5S rDNA loci that were smaller than those on marker chromosomes 1 . It could be seen in mitotic metaphases that one of the marker chromosomes 1 had a smaller $5 \mathrm{~S}$ locus and one of the three marker chromosomes 2 had a larger $5 \mathrm{~S}$ locus but, as the different signal sizes could not be resolved at meiosis, these chromosomes were not given individual identities. Marker chromosomes 3 and 4 carried 18S-26S rDNA loci that were, respectively, larger and smaller than those of marker chromosomes 1 . The locus on chromosome 4 was sometimes undetectable due to its small size, and at the prometaphase of mitosis (not shown) it lacked a secondary constriction, suggesting that it was silent at the preceding interphase. Marker chromosomes 5 and 6 carried larger $5 \mathrm{~S}$ rDNA loci than marker chromosomes 1 and 2, the larger of these being on chromosome 5 .

At meiosis in PMCs of the pentaploid R. canina, two of the marker chromosomes 1 and two of the marker chromosomes 2 formed bivalents (Figure $2 g$ and $h$ ). The other chromosomes remained as univalents. Of these, marker chromosomes 1 and marker chromosomes 3, 5 and 6 were regularly detected, but one of the marker chromosomes 2 and marker chromosome 4 were only occasionally seen. In the gynogenetic haploid, four 1826S rDNA loci were seen at metaphase I of meiosis, two of chromosome type 1, one each of chromosome types 3 and 4 . FISH with 5S rDNA was attempted unsuccessful 

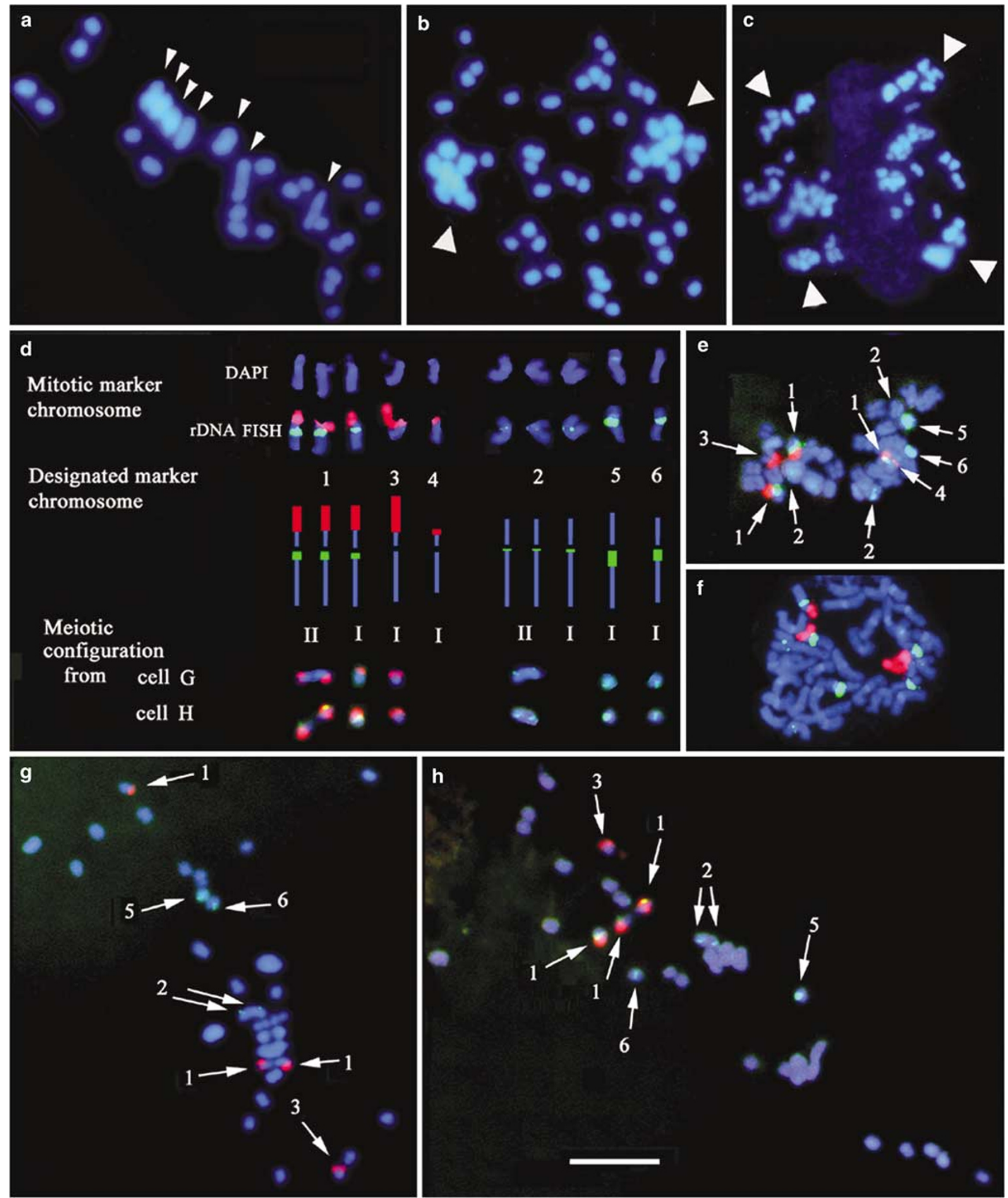

Figure 2 Meiotic cells in pentaploid R. canina stained with DAPI (a-c), and analysis of marker chromosomes (d) from mitotic (e, f) and meiotic metaphases $(\mathbf{g}, \mathbf{h}$ ) after FISH with 18-26S rDNA (in red) and 5S rDNA (in green). (a) Metaphase I showing seven bivalents (arrow heads); (b) anaphase I showing the segregated bivalents at the poles (arrow heads) and the separation of two groups of chromatids from the 21 univalents; (c) anaphase II showing four clusters of seven bivalent-derived chromosomes (arrow heads) and undivided chromatids from the univalents; (d) analysis of marker chromosomes: top two rows show chromosomes at mitosis from cell in (f) without and with probes, respectively, the middle row shows a karyogram, bottom two rows show meiotic bivalents (II) and univalents (I) from cells in (g) and (h); (e, f) metaphase of mitosis showing the marker chromosomes indicated by numbered arrows; ( $\mathrm{g}, \mathbf{h})$, metaphase I of meiosis showing bivalent and univalent marker chromosomes indicated by numbered arrows. Scale bar $=10 \mu \mathrm{m}$. 
Table 1 Chromosome pairing at metaphase I of meiosis in PMCs of $R$. canina and the gynogenetic haploid derived from $R$. canina (based on the analysis of 50 cells per plant)

\begin{tabular}{lcccc}
\hline Plant & $\begin{array}{c}\text { Chromosome } \\
\text { counts }\end{array}$ & \multicolumn{2}{c}{$\begin{array}{c}\text { Mean chromosome associations per } \\
\text { cell at metaphase I of meiosis }\end{array}$} \\
\cline { 2 - 5 } & & Univalents & Bivalents & Trivalents \\
\hline $\begin{array}{l}\text { R. canina } \\
\begin{array}{l}\text { Gynogenetic } \\
\text { haploid }\end{array}\end{array}$ & $2 n=5 x=35$ & 28 & 7 & 0 \\
\hline
\end{tabular}

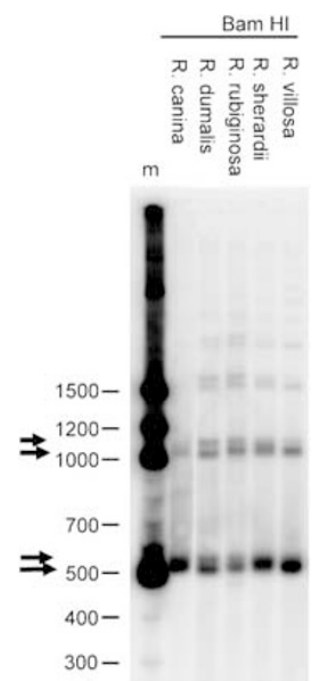

Figure 3 Southern hybridization of five species of the Caninae after Bam $\mathrm{H} 1$ digestion. $R$. canina, $R$. dumalis and $R$. rubiginosa show approximately equimolar amounts of two $5 \mathrm{~S}$ rDNA families (unit length $510,550 \mathrm{bp}$ and $1020,1100 \mathrm{bp}$ indicated by arrows), whereas $R$. sherardii and, especially, $R$. villosa have more of the shorter family. A molecular ladder and base pair numbers are indicated.

and could not be repeated because of shortage of flower buds.

\section{Two classes of 5 S rDNA in the Caninae}

BamH1 digestion of rDNA from five species of the Caninae was followed by gel electrophoresis and Southern hybridization. Two families of 5S rDNA unit (unit length 510, 550 bp) were revealed in each species (Figure 3). In R. canina, R. dumalis and R. rubiginosa, they occurred in nearly similar copy numbers, but in $R$. sherardii and especially $R$. villosa there was relatively more of the shorter length variant. This is seen most clearly in the 1020 and $1100 \mathrm{bp}$ dimers (Figure 3).

\section{Discussion}

Five chromosomes of $R$. canina carry a terminal 18S-26S rDNA locus and five chromosomes carry a paracentric $5 S$ rDNA locus, but no 18S-26S rDNA locus (Figure 2a). It might be expected that chromosomes with rDNA loci would have equivalent representation in each of the five genomes of this pentaploid species. However, whereas three of the five chromosomes with 18S-26S rDNA loci also carried 5S rDNA loci, two did not. Possibly, paracentric 5S rDNA loci were lost from marker chromosomes 3 and 4 during the evolution of the Caninae. The presence of two 5S rDNA loci per genome in the diploid species $R$. multiflora (Mishima et al, 2002) and one 18S-26S rDNA locus per genome in most of the rose species investigated by Ma et al (1997) and Fernandez-Romero et al (2001) is consistent with this argument. Ma et al (1997) found one 18S-26S rDNA locus per genome, located terminally on the short arms of small submetacentric chromosomes, in five diploid species and one tetraploid cultivar of Rosa. FernandezRomero et al (2001) found one 18S-26S rDNA locus per genome in terminal locations on submetacentric chromosomes of five diploid species and subtelocentric chromosomes in a triploid form of $R$. chinensis. However, Fernandez-Romero et al (2001) found a total of six sites in terminal locations on the short arms of submetacentric chromosomes of a tetraploid species, R. gallica, indicating that it contains a pair of genomes with two 18S-26S rDNA loci in addition to a pair with one 18S-26S locus. In the present investigation, two types of $5 \mathrm{~S}$ rDNA were found in relative amounts that vary between species. This indicates that refinement of FISH studies, using the two types of rDNA separately, may facilitate further characterization of the genomes of $R$. canina and more precise comparisons between the genomes of different species.

The presence of three marker chromosomes 1 and three marker chromosomes 2 suggests that there might be three homologous genomes in $R$. canina. However, this seems unlikely because no trivalents were seen in the pentaploid $R$. canina, the frequency of chromosome pairing in the gynogenetic haploid was low and the molecular evidence (Werlemark et al, 1999; Wissemann, 1999; Nybom et al, 2004) indicates that only two of the five genomes of $R$. canina are closely similar. However, the formation of bivalents and trivalents in the gynogenetic haploid, albeit in low frequency, also demonstrates a limited potential for chromosome pairing between genomes of $R$. canina that was not expressed in the pentaploid. If the proposed alleles responsible for suppressing pairing of the univalent chromosomes are located on the pairing genomes (Werlemark, 2003), this gene would be hemizygous in the gynogenetic haploid and its influence might be only partially expressed.

If the matroclinal system of the Caninae evolved only once (Blackhurst, 1948; Werlemark, 2003; Nybom et al, 2004) and the genes that suppress homeologous pairing are located on the pairing chromosomes (Werlemark, 2003), bivalent-forming chromosomes throughout the Caninae are likely to be of common origin. This possibility is supported by the evidence of Nybom et al (2004) that the alleles shared by three pentaploid and one tetraploid species reside on the bivalent-forming chromosomes, whereas species-specific alleles reside on the univalent-forming chromosomes. Nybom et al (2004) suggested that the matroclinal inheritance of the Caninae evolved in an ancestral triploid hybrid between a diploid and a tetraploid species $(\mathrm{AA} \times \mathrm{AABB})$. It is equally likely that it evolved in an ancestral tetraploid hybrid between two tetraploid species that shared a common genome $(\mathrm{AABB} \times \mathrm{AACC})$. Pentaploid and hexaploid species could have arisen by further hybridization with polyploid species which shared a common genome (eg $\mathrm{AABC} \times \mathrm{AADD}$ and $\mathrm{AABC} \times \mathrm{AADDEE})$, provided that 
the progenitor species with the canina-type mechanism was the female parent.

Evidence has been presented in this paper, and the references cited, that only two genomes are involved in bivalent formation in $R$. canina and that differences between the other three genomes, possibly reinforced by genetic control mechanisms, prevent them from pairing. Thus, it follows that three genomes are never, or only rarely, involved in pairing. The evolutionary fate for such chromosomes is genetic degradation through accumulated mutational change (as in the evolution of the mammalian $\mathrm{Y}$ chromosome). Evidence in favour of this hypothesis is the heteromorphic FISH signals to the univalent marker chromosomes, which indicate genetic divergence. In ancient asexual species, predicted genetic outcomes of a lack of recombination are structural heterozygozity of the karyotypes and allelic heterozygozity (Normark et al, 2003). Both phenomena are observed for the univalent genomes, which are probably inherited without recombination and can therefore be considered in evolutionary terms as 'asexual' chromosomes. If the 21 univalents were not involved in recombination, then it would be predicted that over time they will degrade, become redundant and may even be lost. If these arguments are correct, the six nonpairing $5 S$ rDNA loci might be expected to show 5S family divergence on the univalent-forming chromosomes; yet two distinct families were observed, with no evidence of $5 S$ family degeneracy (which occurs as smears on Southern hybridization as previously observed in Nicotiana setchellii; Matyášek et al, 2002). Therefore, the data point to a recent univalent/bivalent demarcation in the evolution of $R$. canina. Further investigations, in which FISH may play an important part, are needed to determine whether or not the pairing genomes in the different species of the Caninae have originated from a single common ancestor.

\section{Acknowledgements}

We thank the Erik Philip-Sörensson Foundation and Royal Swedish Academy of Agriculture and Forestry (SJFR) and the NERC (UK) for financial support.

\section{References}

Blackburn K, Heslop-Harrison JW (1921). The status of the British rose forms as determined by their cytological behaviour. Ann Bot 35: 159-188.

Blackhurst HT (1948). Cytogenetic studies on Rosa rubiginosa and its hybrids. Proc Am Soc Hort Sci 52: 510-516.

Darlington CD (1965). Cytology. J and A Churchill: London.

Erlanson EW (1933). Chromosome pairing, structural hybridity and fragment in Rosa. Bot Gazette 94: 551-566.

Fernandez-Romero MD, Torres AM, Millan T, Cubero JI, Cabrera A (2001). Physical mapping of ribosomal DNA on several species of the subgenus Rosa. Theor Appl Genet 103: 835-838.

Fulnecek J, Lim KY, Leitch AR, Kovarik A, Matyasek R (2002). Evolution and structure of $5 \mathrm{~S}$ rDNA loci in allotetraploid Nicotiana tabacum and its putative parental species. Heredity 88: $19-25$.

Grant V (1981). Plant Speciation, 2nd edn. Columbia University Press: New York.
Gerlach WL, Bedbrook JR (1979). Cloning and characterization of ribosomal RNA genes from wheat and barley. Nucl Acids Res 7: 1869-1885.

Gustafsson $\AA$ (1944). The constitution of the Rosa canina complex. Hereditas 30: 405-428.

Holm S (1995). Unexpectedly high levels of genetic variation in Potentilla argentea L. (s.l.) in southern Sweden. Hereditas 123: 127-139.

Hurst CC (1931). Embryo-sac formation in diploid and polyploid species of Roseae. Proc R Soc London (Ser B) 109: 126-148.

Jones RN, Rees H (1982). B Chromosomes, 1st edn. Academic Press: New York.

Leitch AR, Lim KY, Webb DR, Mcfadden GI (2001). In situ hybridiastion. In: Hawes C, Satait-Jeunemaitre B (eds) Plant Cell Hybidisation, Practical Approach Series. Oxford University Press: Oxford. pp 267-293.

Lim KB, Ramanna MS, de Jong JH, Jacobsen E, van Tuyl JM (2001). Indeterminate meiotic restitution (IMR): a novel type of meiotic nuclear restitution mechanism detected in interspecific lily hybrids by GISH. Theor Appl Genet 103: 219-230.

Ma Y, Islam-Faridi MN, Crane CF, Ji Y, Stelly DM, Price HJ et al (1997). In situ hybridisation of ribosomal DNA to rose chromosomes. J Heredity 88: 158-161.

Matyášek R, Fulneèek J, Lim KY, Leitch AR, Kovaøík A (2002). Evolution of $5 \mathrm{~S}$ rDNA unit arrays in the plant genus Nicotiana (Solanaceae). Genome 45: 556-562.

Mishima M, Ohmido N, Fukui K, Yahara T (2002). Trends in site-number change of rDNA loci during polyploid evolution in Sanguisorba (Rosaceae). Chromosoma 110: 550-558.

Meynet J, Barrade R, Duclos A, Siadous R (1994). Dihaploid plants of roses (Rosa hybrida) obtained by parthenogenesis induced using irradiated pollen and in vitro culture of immature seeds. Agronomie 2: 169-175.

Normark BB, Judson OP, Moran NA (2003). Genomic signatures of ancient asexual lineages. Biol J Linn Soc 79: 69-84.

Norrmann GA, Quarin CL (1987). Permanent odd ploidy in grass (Andropogon ternatus). Genome 29: 340-344.

Nybom H, Esselink DG, Werlemark G, Vosman B (2004). Microsatellite DNA marker inheritance indicates preferential pairing between highly homologous genomes in polyploid and hemisexual dog-roses Rosa L.0 sect. Caninae. Heredity 92: 139-150.

Roberts AV (1975). The nature and taxonomic significance of the system of inheritance in Rosa nanothamnus (Rosaceae). Bot J Linn Soc 71: 59-66.

Sambrook J, Fritsch EF, Maniatis T (1989). Molecular Cloning: A Laboratory Manual, 2nd edn. Cold Spring Harbor Laboratory Press: Cold Spring Harbor, USA.

Smith-White S (1948). The life history and genetic system of Leucopogon juniperinus. Heredity 9: 79-91.

Täckholm G (1922). Zytologische Studien über die Gattung Rosa. Acta Hort Bergiani 7: 97-112.

Uggla M, Nybom H (1999). Domestication of a new crop in Sweden - dog roses (Rosa sect. Caninae) for commercial rose hip production. Acta Hortic 484: 147-151.

Werlemark G (2003). Inheritance in the dog rose. In: Roberts AV, Debener T, Gudin S (eds) Encyclopedia of Rose Science. Elsevier Ltd: Oxford, San Diego. pp 292-299.

Werlemark G, Uggla M, Nybom H (1999). Morphological and RAPD markers showed a highly skewed distribution in a pair of reciprocal crosses between hemisexual dogroses, Rosa section Caninae. Theor Appl Genet 98: 557-563.

Wissemann V (1999). Genetic constitution of Rosa section Caninae ( $R$. canina, $R$. jundzillii) and sect. Gallicanae (R. gallica). J Appl Bot 73: 191-196.

Wylie AP (1976). Why the Caninae roses are different!. NZ Rose Аппи 67-79. 